Katarina Njegić ${ }^{*}$, Ines Djokić ${ }^{2}$, Vesna Milanović ${ }^{3}$ ${ }^{1}$ Faculty of Business Economics and Entrepreneurship, Belgrade, Serbia

${ }^{2}$ University of Novi Sad, Faculty of Economics in Subotica, Serbia 3"Union - Nikola Tesla" University, Faculty of Business and Law, Belgrade, Serbia

\title{
Testing MKTOR Scale Properties in Serbian Exporters' Context
}

DOI: 10.7595/management.fon.2019.0011

\begin{abstract}
:
Research Question: This paper investigates whether the Narver and Slater's market orientation scale (MKTOR scale) is reliable, valid and applicable in the Serbian exporters' context. Motivation: Previous studies that examined the applicability of the MKTOR scale report inconsistent results (Matsuno, Mentzer, \& Rentz 2005; Ward, Girardi, \& Lewandowska, 2006; Rojas-Mendez, \& Rod, 2013) and the studies that use MKTOR scale in export performance research are scarce. Therefore, the aim of this paper was to examine psychometric properties of the MKTOR scale based on the data gathered from Serbian exporters. Idea: The core idea of this paper was to empirically evaluate reliability, convergent, discriminant and nomological validity of the the MKTOR scale. Data: In order to collect data for the analysis, an on-line survey was conducted which related to the business year 2017. It involved 60 managers of exporting firms in the Republic of Serbia. Tools: The statistical methods used were exploratory factor analysis, confirmatory factor analysis and path analysis through partial least squares. Findings: The obtained results indicate that the original the MKTOR scale satisfies the reliability and convergent validity criteria. Since the MKTOR scale did not demonstrate adequate discriminant validity, a refined scale was proposed. The results of the research shown that the MKTOR consists of three separate components that can be used as independent measurement scales. A statistically significant positive relationship was found between market orientation measured with the MKTOR scale and the overall satisfaction with export performance, which demonstrates the nomological validity of the examined scale. The obtained results contribute to the external validation of the MKTOR scale. The results are valuable since they provide researchers from Serbia with the reliable measurement instrument that can be used for the empirical investigation of market orientation and its various influential factors. Contribution: This paper contributes to the existing literature by providing the evidence from the context in which the scale was not tested before. The paper demonstrates the usefulness of the MKTOR scale in predicting export performance. This paper expands the existing research related to the applicability of the MKTOR scale and it formulates practical suggestions of the way market orientation can be operationalized in export performance research.
\end{abstract}

Keywords: market orientation, MKTOR scale, export performance, validity

JEL Classification: M31, F23

\section{Introduction}

Market orientation (MO) is a central concept in the marketing management theory. Because of its fundamental importance, MO is constantly attracting attention of the researchers (Cacciolatti, \& Lee, 2016; Acosta, et al., 2018). There were numerous attempts to define this significant concept (Shapiro, 1988; Ruekert, 1992; Deshpande, \& Farley, 1998), but only two of them gained wide acceptance of the scientific community. The first one is the concept proposed by Kohli and Jaworski (1990) which is often referred to as a behavioural perspective. Narver and Slater (1990) presented the second approach, which is often called cultural perspective. These two seminal works were a turning point in the marketing research literature because not only did the authors propose definitions of $\mathrm{MO}$, but they also developed scales for measuring the level of implementation of $\mathrm{MO}$ in practice. This way they shifted the focus from descriptive explanation to empirical testing of the MO concept. Kohli and Jaworski defined MARKOR scale (Kohli, et al., 1993) while Narver and Slater (1990) designed a 15-item scale, which they called the MKTOR. 
Since the scales were developed based on business practice of firms operating in the United States, studies of Kohli and Jaworski and Narver and Slater encouraged researchers to evaluate the applicability of these scales in different macroeconomic environments. Moreover, the development of measuring instruments inspired a plethora of new empirical studies as it enabled the investigation of antecedents and consequences of MO. At first, the emphasis was on determining the impact of MO on business performance (Cano, et al., 2004; Frosen, et al., 2016; Takata, 2016). However, in the last decade, MO especially attracts attention of the researchers in the field of export performance (EP), and today $\mathrm{MO}$ is considered as one of its main determinants (Sousa, 2008; Chen, et al., 2016; He, et al., 2018).

In previous research on the relationship between $\mathrm{MO}$ and EP, the cultural perspective has been neglected and the researchers mainly use the behavioural approach (Radosavljevic, \& Milanovic, 2017), regardless of the fact that both perspectives are recognized as equally important (Deshpande, \& Farley, 1998; Shoham, et al., 2005). A specific concept developed for testing the MO in export context (Cadogan, et al., 1999) is also behavioural in its essence (Radosavljevic, 2017). Therefore, the applicability of the MKTOR scale in EP research is not sufficiently explored.

Findings from previous studies indicate potential validity issues of the MKTOR scale (Ward, et al., 2006; Rojas-Mendez, \& Rod, 2013). There is also a question regarding the dimensionality of the scale (Siguaw, \& Diamantopoulos, 1995; Hooley, et al., 2000; Ward, et al., 2006). The majority of the studies that explore antecedents and consequences of $\mathrm{MO}$ in domestic context, as well as the studies on the relationship between MO and EP, were conducted in Western countries (Radosavljevic, \& Milanovic, 2017; Njegic, \& Djokic, 2018). Therefore, there is little research from developing world, especially from Eastern European countries.

The purpose of this paper is to analyse psychometric properties of the MKTOR scale based on the data gathered from Serbian exporters. The contribution of this kind of research is twofold. First, the examination of the MKTOR scale properties will be performed in the context in which it was not performed before. Moreover, this research can demonstrate whether the MKTOR is useful for predicting EP. From the practical point of view, establishing reliability and validity of the MKTOR scale will provide researchers from Serbia with the reliable measuring instrument that can be used for empirical investigation of MO and its various influential factors. This can stimulate and facilitate further research in the field of $\mathrm{MO}$ in Serbia and in other developing countries.

The paper is organized as follows. In the second section, the theoretical background for the research is presented along with the review of previous literature in the related field. In the third section the applied research methodology is explained. The fourth section presents the results of the conducted research. Implications of the results are described in section five (Discussion). In the sixth section, conclusions are drawn along with the limitations and directions for future research.

\section{Theoretical Background and the Review of Previous Empirical Research}

Narver and Slater emphasize that the ability of a firm to achieve superior performance depends on its ability to create sustainable competitive advantage (Narver, \& Slater, 1990). Furthermore, they state that if a firm wants to achieve this goal, it has to possess an organizational culture that stems from the desire to create superior value for its consumers. According to the authors, MO consists of three separate dimensions: customer orientation, competition orientation and interfunctional coordination. Narver and Slater formulated $\mathrm{MO}$ as "one-dimensional construct consisting of three distinct equally important components" (1990, p.22). They also state that there is "a strong correlation among the three components of MO which indicates that they are converging on a common construct" $(1990$, p.25). However, empirical studies that examined the applicability of the MKTOR scale report on some validity issues and the results regarding dimensionality of the scale are inconsistent.

Siguaw and Diamantopoulos (1995) were among the first authors who investigated the validity of Narver and Slater's MO construct. While reliability tests showed internal consistency of all three dimensions, confirmatory factor analysis (CFA) that authors conducted did not give satisfactory results. Neither onefactor model (which represented unidimensional construct) nor a three-factor model (which represented $\mathrm{MO}$ as three separate dimensions) showed an adequate data fit. By conducting an exploratory factor analysis (EFA) they have discovered that some of the items that represent competitor orientation and interfunctional coordination did not load well on the related factors or that the items that represent different dimensions cross-loaded heavily. 
Farrell and Oczkowski (1997) conducted their analysis in Australia on a sample consisting of firms different in sizes and from different industries. The results of the CFA indicated that the original model of $\mathrm{MO}$ proposed by Narver and Slater (1990) was not appropriate. The authors managed to obtain an adequate model fit by removing some items from the scale.

Hooley and his colleagues (2000) tested the MKTOR scale in Slovenia, Hungary and Poland. Reliability analysis in this study showed that competitor orientation and interfunctional coordination are unreliable as separate scales. The authors' further analysis revealed that the MKTOR scale is reliable only when it is used as one-dimensional construct, computed as the average score of all items.

Matsuno, Mentzer and Rentz (2005) compared the MARKOR (Kohli, et al, 1993), EMO (Cadogan, 1999) and MKTOR scales. Their CFA at first-order level did not produce acceptable general fit indices. When they formulated the MKTOR as a second-order construct, they got an excellent fit statistics. However, they reported that the reliabilities of customer orientation and competitor orientation sub-scales were not high. They concluded that from the three compared scales, the MKTOR was the most efficient in predicting performance measures and that it was superior on the criterion of variance extracted.

One of the main questions Ward, Girardi and Lewandowska (2006) posed was the dimensionality of the MKTOR scale. They have found that it is a three-dimensional construct rather than one-dimensional construct. Ward and his colleagues had to drop a few items from the scale to improve the model fit and to establish a discriminant validity of the scale.

Rojas-Mendez and Rod (2013) investigated psychometric properties of the MARKOR and MKTOR scales. They first conducted EFA, which did not generate a clear pattern matrix. After they removed indicators with low factor loadings, 10 items remained, and this refined scale they used in further analysis. For the refined scale, they established a reliability and discriminant validity. They also presented evidence of a good predictive validity of the MKTOR scale.

Regarding the applicability of the MKTOR scale in the export context, there is little research. Few studies that used the MKTOR in examining the relationship between MO and EP report on positive results (Behboodi, \& Shagerdi, 2013; Julian, et al., 2014; Zehir, et al., 2015; Olabode, et al., 2018). Thus, it can be assumed that the nomological validity in the Serbian context is going to be confirmed, i.e., that the relationship between $\mathrm{MO}$ and EP is going to be positive and statistically significant.

The presented literature review suggests that there is a dilemma regarding the applicability of the MKTOR scale and that additional research is needed. Therefore, the aim of this paper is to add to the existing gap in the literature by providing answers to the following questions:

1) Is the MKTOR scale reliable and valid in the Serbian context? The answer to this question will contribute to the validation of the scale in the new context.

2) Is it a one-dimensional construct or rather a three-dimensional construct? This will add to the evidence about the dimensionality of the scale.

3) Could the scale be used to predict EP of Serbian exporting firms? From the answer, it will be possible to establish its nomological validity in the Serbian context.

\section{Research Methodology}

\subsection{Sample and data collection}

The data were collected through structured questionnaire. The survey was conducted on-line (using Google Forms) at the beginning of 2018, and it related to the business year 2017. The firms that exported from Serbia in the year 2017 formed the target population. The contacts of the managers responsible for exporting were acquired through the suppliers' database on the website of the Development Agency of Serbia (http://www.ras.gov.rs/en/export-promotion/serbian-suppliers-database, accessed on: 22nd Nov.2017). Those were the key respondents. Firms from different sectors and different sizes were selected for the sample. A multi-industry sample was used in previous research and it is stated that this allows the generalizability of the results (Farrell, \& Oczkowski, 1997; Hooley, et al., 2000; Matsuno, et al., 2005). There were 321 manufacturing firms available in the database and they were selected for the survey. In order to inform the participants about the content and purpose of the research, they were primarily contacted by telephone. A total of 305 participants gave their consent to participate in the survey, and immediately after 
the telephone call, they were sent an email with a link to the electronic questionnaire. From the 305 questionnaires sent, 60 complete questionnaires returned which makes the response rate of $19.7 \%$. A similar response rate appears in other studies in this area (see literature review: Chen, et al., 2016). Out of 60 firms in the sample, the majority are from the food, beverage and agriculture sectors (26 firms). There are 15 firms from the plastics, chemistry and rubber industry, and nine firms from the textile and clothing industry. The remaining firms in the sample are from the wood and paper industry (6 firms), as well as from other industries (furniture-2, leather -1, footwear -1). Small and medium-sized firms prevail in the sample (small-29, medium20 , large -11). Although the sample size is modest, the sample can be considered relevant, since previous studies report on similar sample size (see: Ward, et al., 2006; Rojas-Mendez, \& Rod, 2013).

\subsection{Constructs' measurements}

The original MKTOR scale consisting of 15 items was used for measuring MO (Narver, \& Slater 1990; 1994). The customer orientation sub-scale (CustOr) is composed of six items; competitor orientation sub-scale (CompOr) includes four items and interfunctional coordination sub-scale (IFC) contains five items. Following the previous research (Hansen, et al., 2006), items were listed randomly in the questionnaire (see Appendix). The respondents were asked to what extent they agree with the presented statements (1-do not agree at all; 5-completely agree). Relying on previous research (Racela, et al., 2007; Julian, et al., 2014; Fuchs, \& Kostner, 2016), EP was measured as the level of overall satisfaction with export performance (1-not satisfied at all; 5completely satisfied).

\subsection{Data analysis}

The data were analysed using different techniques, depending on the objective. Reliability analysis was conducted by estimating Cronbach's alpha in SPSS 25.0. In order to explore the dimensionality of the scale first the exploratory factor analysis (EFA) in SPSS 25.0 was conducted. The EFA is a good technique for preliminary testing of the scale construction, but it is not sufficient and subsequently the CFA is recommended (Gerbing, \& Anderson, 1988). Therefore, confirmatory factor analysis (CFA) in AMOS 22.0.0. was conducted. Convergent and discriminant validities were assessed based on the results obtained through the CFA. For the assessment of predictive power of MKTOR scale, a partial least squares technique (PLS) was used and the analysis was conducted in software SmartPLS 3.7.7. PLS was shown to be a reliable technique when dealing with small samples (Hair, et al., 2019).

\section{Results}

Reliability of the scale. The reliability of all three sub-scales was tested, as well as the reliability of the MKTOR scale as a whole. The obtained results indicate that there are no reliability concerns (CustOr $=0.916$, CompOR $=0.863, \mathrm{IFC}=0.896, \mathrm{MKTOR}=0.947)$, since Cronbach's alpha for all scales is above the required threshold of 0.7 (Churchill, 1979; Cortina, 1993).

Dimensionality of the scale. The first objective was to investigate the underlying factor structure of the MO construct. For these purposes, EFA was conducted. The number of factors was fixed to three in order to examine whether the items load well on the factors that they were supposed to load on considering the theoretical framework. The principal component analysis (PCA) was used as the extraction method and Promax as the rotation method. The Narver and Slater's model assumes three distinct dimensions that are highly correlated. It is suggested that oblique rotation methods be used if the underlying factors of the examined construct are correlated (Hair et al., 2010). Moreover, the combination of PCA and Promax was used in previous research (Zehir, et al., 2015). In order to ensure that the data set is adequate for performing EFA, Kaiser-Meyer-Olkin (KMO) measure of sampling adequacy was analysed and the Bartlett's test of sphericity was performed. The level of the KMO index was shown to be high enough (0.908) suggesting that the data may be grouped into a smaller set of underlying factors (Kaiser, 1974). The result of Bartlett's test $($ Sig. $=0.000)$ indicted that the variables do relate to one another enough to perform a meaningful EFA (Nunnally, 1978).

The three extracted factors explained $73.195 \%$ of the total variance in the model. However, the generated pattern matrix did not show good results. The majority of the item loadings were high (above 0.5, except for one item), but there were some items that cross-loaded. Following previous research (Farrell, \& Oczkowski, 1997; Ward, et al., 2006; Rojas-Mendez, \& Rod, 2013), the scale was refined by deleting the items that loaded on more than one factor. The cleaner version of the pattern matrix was accomplished by deleting four 
items. Three extracted factors together explained $76.413 \%$ of the total variance in the refined model. The results are presented in Table 1. Following the suggestions in the literature (Hair et al., 2010), minimal adjustments of the original scale were done, in order to remain true to the theoretical model. Thus, even though more items could be deleted based on the factor loadings (CustOr3 and IFC4), they were retained in order to preserve the content validity of the scale. For further analysis, the refined scale was compared with the original in order to further investigate the dimensionality through the CFA. All of the items that formed the refined scale, as well as deleted items are given in the Appendix.

Table 1: Pattern matrix generated for the refined MKTOR scale

\begin{tabular}{|l|c|c|c|}
\hline Items & \multicolumn{3}{|c|}{ Component* $^{\star}$} \\
\hline CustOr3 & $\mathbf{1}$ & $\mathbf{2}$ & $\mathbf{3}$ \\
CustOr4 & .238 & $\mathbf{5 7 7}$ & .064 \\
CustOr5 & .036 & .977 & -.118 \\
CustOr6 & .097 & .803 & .046 \\
CompOr1 & -.142 & .767 & .264 \\
CopmOr2 & -.110 & .187 & .824 \\
CompOr4 & -.049 & .001 & .937 \\
IFC1 & .291 & -.114 & .756 \\
IFC2 & .895 & -.014 & -.020 \\
IFC4 & .882 & -.135 & .150 \\
IFC5 & .675 & .295 & -.110 \\
\hline
\end{tabular}

*Factor loadings above 0.5 are highlighted.

Source: authors' research

Relying on the theoretical framework (Narver, \& Slater, 1990) and previous research (Ward, et al., 2006), four competing models were defined. The aim was to compare which of the defined models best explains the real nature of the $\mathrm{MO}$ construct. The original model (scale composed of 15-items) was compared to the refined scale (11-items) and both of these models were examined as a one-factor model and a three-factor model. The results of the CFA are given in Table 2.

Table 2: The comparison of MO measurement models

\begin{tabular}{|l|c|c|c|c|c|c|c|c|}
\hline \multirow{2}{*}{ Competing model } & \multicolumn{9}{|c|}{ Goodness-of-Fit Measures } \\
\cline { 2 - 9 } & $\chi^{2}$ & df & p-value & $\chi^{2}$ /df & SRMR & RMSEA & CFI & PNFI \\
\hline $\begin{array}{l}\text { M1: One-factor } \\
\text { model (15 items) }\end{array}$ & 102.729 & 90 & 0.163 & 1.141 & 0.019 & 0.049 & 0.510 & 0.185 \\
$\begin{array}{l}\text { M2: Three-factor } \\
\text { model (15 items) }\end{array}$ & 87.911 & 87 & 0.453 & 1.010 & 0.015 & 0.013 & 0.965 & 0.272 \\
$\begin{array}{l}\text { M3: One-factor } \\
\text { model (11 items) }\end{array}$ & 73.140 & 44 & 0.004 & 1.662 & 0.231 & 0.106 & 0.361 & 0.218 \\
$\begin{array}{l}\text { M4: Three-factor } \\
\text { model (11 items) }\end{array}$ & 45.517 & 41 & 0.291 & 1.110 & 0.021 & 0.043 & 0.901 & 0.408 \\
\hline
\end{tabular}

2- chi-square; df-degrees of freedom; 2/df- normed chi-square; SRMR-standardized root mean residual; RMSEA-root mean square error of approximation; CFI-comparative fit index; PNFI-parsimony normed fit index.

Source: authors' research

Based on the indices presented in Table 2, the fourth model (three-factor, 11-items) has the best fit. Basic goodness of fit measures (chi-square, degrees of freedom and p-value) and absolute fit indices (normed chisquare, SRMR, RMSEA) are acceptable for all models except for the third model (the thresholds were taken from Hu, \& Bentler, 1999; Hair et al., 2010). However, the CFI index should be above 0.9 (Hair et al., 2010; Brown, 2014) and for $M 1$ and $M 3$ it is unacceptable, which is a clear indication that these two models are not suitable. Comparing PNFI for M2 and M4, it can be concluded that M4 overperformed M2, since the higher value of this index is preferable (Hair et al., 2010; Brown, 2014).

Validity of the scale. Convergent and discriminant validity of the original and the refined scale were estimated based on the results obtained through the CFA. The composite reliability (CR), average variance extracted $(\mathrm{AVE})$, maximum shared variance (MSV) were calculated as well as the correlations between constructs. The results are presented in Table 3. The values on the diagonals (bold values) are square root of constructs' AVEs and the values below the diagonals represent inter-correlations between constructs. 
Table 3: Convergent and discriminant validity of the original and refined MKTOR scale

\begin{tabular}{|c|c|c|c|c|c|c|}
\hline $\begin{array}{l}\text { Original MKTOR scale } \\
\text { (15-items, three-factor model) }\end{array}$ & CR & AVE & MSV & CustOr & CompOr & IFC \\
\hline CustOr & 0.957 & 0.790 & 0.810 & 0.889 & & \\
\hline CompOr & 0.902 & 0.698 & 0.810 & $0.900 * * *$ & 0.836 & \\
\hline IFC & 0.930 & 0.727 & 0.737 & $0.829 * * *$ & $0.859 * * *$ & 0.853 \\
\hline $\begin{array}{l}\text { Refined MKTOR scale (11-items, } \\
\text { three-factor model) }\end{array}$ & CR & AVE & MSV & CustOr & CompOr & IFC \\
\hline CustOr & 0.920 & 0.741 & 0.552 & 0.861 & & \\
\hline CompOr & 0.891 & 0.733 & 0.535 & $0.731^{\star * \star}$ & 0.856 & \\
\hline IFC & 0.914 & 0.726 & 0.552 & $0.743^{\star * \star}$ & $0.603^{* * *}$ & 0.852 \\
\hline
\end{tabular}

Source: authors' research

Both original and the refined scale did not demonstrate convergent validity issues. Standardized loading estimates for both scales were all above 0.7 , which shows that items load well on the dimensions they were assigned to (Carmines \& Zeller, 1979; Bacon, et al., 1995; Hair et al., 2010). As it is presented in Table 3, AVE values for all constructs and for both scales were greater than 0.5 and CR values were all above 0.7 , which suggests an adequate convergent validity of both scales (Nunnally, 1978; Hair et al., 2010). However, the results show that the original 15-item scale did not satisfy requirements regarding discriminant validity. In the case of original scale, MSV values were higher than AVE values for all constructs. In addition, the square root of the AVE for CustOr is lower than its correlation with CompOr and the square root of the AVE for CompOr is lower than its correlation with IFC. On the other hand, the refined scale satisfies the discriminant validity criteria (MSV<AVE; square root of AVE> inter-construct correlations; see: Fornell, \& Larcker, 1981; Hair et al., 2010). Another important finding of the conducted analysis is that the components of $\mathrm{MO}$ are shown to be highly correlated $(p<0.001)$. In order to ensure that the elimination of the items in the refined scale did not change its reliability, Cronbach's alpha was calculated for the refined scale and its components. The reliability analysis gave satisfactory results $(\alpha>0.7$ for all constructs: CustOr $=0.879$, CompOr $=0.851, \mathrm{IFC}=0.883, \mathrm{MO}=0.922)$.

Since the original scale demonstrated discriminant validity problems, the refined scale was used for nomological validity assessment. The MO construct was defined as second-order formative construct consisting of three first-order constructs - CustOr, CompOr and IFC. Those first order constructs were defined as reflective. This is in line with the results of the CFA previously conducted which shown that the threefactor model with 11 items had the best fit. In order to examine whether the defined dimensions can form a formative MO construct, bootstrapping with 5000 sub-samples was performed (two-tailed t-test; significance level=0.05). The obtained results showed significant relationship between all three dimensions and $\mathrm{MO}$ construct (CompOr $\rightarrow \mathrm{MO}: \beta=0.308$, t-value =13.241, $p=0.000$; CustOr $\rightarrow \mathrm{MO}: \beta=0.425$, $\mathrm{t}$-value $=17.799$, $p=0.000 ;$ IFC $\rightarrow$ MO: $\beta=0.412$, t-value $=15.688, p=0.000$ ) which confirms that $\mathrm{MO}$ can be formulated as formative construct on the second level.

In order to test the relationship between the MO and the EP, the repeated indicator approach was used (Byrne, 2009; Hair et al., 2010). The results of the bootstrapping (5000 sub-samples; two-tailed t-test; significance level $=0.05$ ) showed that there is a statistically significant positive relationship between $\mathrm{MO}$ and EP $(\beta=0.341$, t-value $=3.206, p=0.001)$. The coefficient of determination $\left(R^{2}\right)$ was used as a measure of predictive accuracy. It shows the proportion of the variance in the endogenous variable (in this case EP) that can be explained by the change in exogenous variable (MO). The obtained value of $R^{2}$ was 0.116 , which means that $\mathrm{MO}$ explained 11.6 percent of the variance in EP. There is no unique rule of thumb for acceptable $\mathrm{R}^{2}$ value since its value depends on the number of exogenous variables under consideration and the research discipline (Hair et al., 2017). In the field of EP, $\mathrm{R}^{2}$ values that are higher than 10 percent are considered satisfactory (Falk \& Miller, 1992; Navarro, et al., 2010; Sousa, et al. 2014). Statistically significant positive relationship between $\mathrm{MO}$ and EP as well as the obtained value of $\mathrm{R}^{2}$ indicate that $\mathrm{MO}$ measured with a refined MKTOR scale can predict EP, which confirms the nomological validity of the scale.

\section{Discussion}

In order to contribute to the validation of the MKTOR scale and to explore the possibility of its application in the export context, a survey was conducted on the sample of exporters from Serbia. The results of the conducted research indicate that the original scale developed by Narver and Slater is reliable, as well as its three sub-scales. The original MKTOR scale also showed an adequate convergent validity. The results of the 
EFA and CFA revealed that the items converge well to the dimensions they were assigned to. These results are in line with the findings of previous research (Matsuno, et al., 2005; Behboodi, \& Shagerdi, 2013; Julian, et al., 2014; Zehir, et al., 2015). However, the research conducted revealed a poor discriminant validity of the original MO construct. The results obtained through EFA and CFA revealed that the dimension competitor orientation overlaps with customer orientation and interfunctional coordination. Previous studies report on the same problem (Siguaw, \& Diamantopoulos, 1995; Ward, et al., 2006; Rojas-Mendez, \& Rod, 2013). In order to obtain a useful scale, the items that overlap were removed. The refined scale was tested and compared with the original MKTOR scale. The comparison of four different models showed that a threedimensional factor model with 11 items best fits the data, which suggests the existence of three separate dimensions (sub-scales). These findings are consistent with the findings of Ward and his colleagues (2006), but they are opposite to the findings of Hooley and his colleagues (2000). It was also found that the MO components are highly correlated, which corresponds to the initial premise of Narver and Slater. The examination of nomological validity confirmed that the MKTOR scale can be successfully used to predict EP, which was also verified in other similar studies (Julian, et al., 2014; Zehir, et al., 2015).

Presented findings have important implications for the researchers in the field of international marketing and management. On the sample of exporters from Serbia, it was demonstrated that the MKTOR in general is a reliable concept that can be used in international context when cultural perspective of $\mathrm{MO}$ is implemented. Concerning the dilemma about the dimensionality of the scale, it was shown that Narver and Slater's MO concept is composed of three separate and highly correlated components. This suggests that the subscales can be used separately, as independent scales. Moreover, this finding implies that MO can be formulated as a second-order formative construct that is determined by three first-order reflective constructs. Since the dimensions are not interchangeable, it is advisable to formulate $\mathrm{MO}$ as a formative construct on the second level. It is not recommended to formulate $\mathrm{MO}$ as one-dimensional construct, since the results showed inadequate data fit for one-dimensional model.

\section{Conclusion}

The research that was conducted and presented in this paper expands the knowledge about the applicability of the MKTOR scale. It demonstrates that the MKTOR scale in general is a reliable and valid instrument that can be used in export context when cultural perspective of $\mathrm{MO}$ is implemented. This research also confirms the findings of the previous studies that indicate that the MKTOR scale suffers from some imperfections that can be reduced by refinement of the scale. Even though this study offers valuable insights, it is essential to note that there are limitations regarding the interpretation of the obtained results. As the survey was conducted in Serbia, one should be cautious with generalizing the results. The conclusions drawn in this paper may eventually be extended to the countries of the same level of development and with similar characteristics of the economy. Although the sample is relevant, the number of firms involved in the survey is modest. Therefore, it would be beneficial to repeat the research with more firms involved. Since the existence of the reliable measuring instrument is crucial for encouraging further research in the field of $\mathrm{MO}$ and there is little evidence from less developed countries, the future research might explore the properties of the MKTOR or other MO scales in different developing countries.

\section{REFERENCES}

[1] Acosta, A. S., Crespo, Á. H., \& Agudo, J. C. (2018). Effect of market orientation, network capability and entrepreneurial orientation on international performance of small and medium enterprises (SMEs). International Business Review, 27(6), 1128-1140. DOI: 10.1016/j.ibusrev.2018.04.004

[2] Bacon, D. R., Sauer, P. L., \& Young, M. (1995). Composite reliability in structural equations modeling. Educational and Psychological Measurement, 55(3), 394-406. DOI: 10.1177/0013164495055003003

[3] Behboodi, O., \& Shagerdi, A. (2013). A study on relationship between market orientations culture and exporting performance: A case study of manufacturing corporations listed on Tehran Stock Exchange. Management Science Letters, 3(12), 2885-2888. DOI:10.5267/j.msl.2013.11.009

[4] Brown, T. A. (2014). Confirmatory Factor Analysis for Applied Research (2nd ed.). Guilford Publications.

[5] Byrne, B. M. (2009). Structural equation modeling with AMOS: basic concepts, applications, and programming (2nd ed.). Abingdon-on-Thames: Routledge. DOI:10.4324/9780203805534

[6] Cacciolatti, L., \& Lee, S. H. (2016). Revisiting the relationship between marketing capabilities and firm performance: The moderating role of market orientation, marketing strategy and organisational power. Journal of Business Research, 69(12), 5597-5610. DOI: 10.1016/j.jbusres.2016.03.067

[7] Cadogan, W. J., Diamantopoulos, A., \& De Mortanges C. P. (1999). A measure of export market orientation: scale development and cross-cultural validation. Journal of International Business Studies, 30(4), 689-707. DOI:10.1057/palgrave.jibs.8490834 
[8] Cano, C.R., Carrillat, F.A. \& Jaramillo, F. (2004). A meta-analysis of the relationship between market orientation and business performance: evidence from five continents. International Journal of research in Marketing, 21(2), 179-200. DOI:10.1016/j.jjresmar.2003.07.001

[9] Carmines, E.G., \& Zeller, R.A. (1979). Reliability and Validity assessment. Sage publications.

[10] Chen, J., Sousa, C. M., \& He, X. (2016). The determinants of export performance: a review of the literature 2006-2014. International Marketing Review, 33(5), 626-670. DOI:10.1108/IMR-10-2015-0212

[11] Churchill Jr G. A. (1979). A Paradigm for Developing Better Measures of Marketing Constructs. Journal of Marketing Research, 16(1), 64-73. DOI:10.2307/3150876

[12] Cortina, J. M. (1993). What is coefficient alpha? An examination of theory and applications. Journal of applied psychology, 78(1), 98-104.

[13] Deshpande, R., \& Farley, J. U. (1998). Measuring market orientation: generalization and synthesis. Journal of market-focused management, 2(3), 213-232. DOI:10.1023/A:1009719615327

[14] Falk, R. F., \& Miller, N. B. (1992). A Primer for Soft Modeling. Akron, OH: University of Akron Press.

[15] Farrell, M. A., \& Oczkowski, E. (1997). An analysis of the MKTOR and MARKOR measures of market orientation: an Australian perspective. Marketing Bulletin-Department of Marketing Massey University, 8, 30-40; available on-line: http://marketing-bulletin.massey.ac.nz/ (last access on: 30th Dec 2018)

[16] Fornell, C., \& Larcker, D. F. (1981). Evaluating structural equation models with unobservable variables and measurement error. Journal of marketing research, 18(1), 39-50.

DOI: $10.1177 / 002224378101800104$

[17] Frosen, J., Luoma, J., Jaakkola, M., Tikkanen, H., \& Aspara, J. (2016). What counts versus what can be counted: The complex interplay of market orientation and marketing performance measurement. Journal of Marketing, 80(3), 60-78. DOI: 10.1509/jm.15.0153

[18] Fuchs, M., \& Köstner, M. (2016). Antecedents and consequences of firm's export marketing strategy: An empirical study of Austrian SMEs (a contingency perspective). Management Research Review, 39(3), 329-355. DOI:10.1108/MRR-07-2014-0158

[19] Gerbing, D. W., \& Anderson, J. C. (1988). An updated paradigm for scale development incorporating unidimensionality and its assessment. Journal of marketing research, 25(2), 186-192. DOI:10.2307/3172650

[20] Hair Jr, J. F., Hult, G. T. M., Ringle, C., \& Sarstedt, M. (2017). A Primer on Partial Least Squares Structural Equation Modeling (2nd ed.). Sage publications.

[21] Hair, J. F., Risher, J. J., Sarstedt, M., \& Ringle, C. M. (2019). When to use and how to report the results of PLS-SEM. European Business Review, 31(1), 2-24. DOI: 10.1108/EBR-11-2018-0203

[22] Hair, J., Black, W., Babin, B., \& Anderson, R. (2010). Multivariate data analysis (7th ed.). Prentice-Hall, Inc. Upper Saddle River, NJ, USA.

[23] Hansen, E., Dibrell, C., \& Down, J. (2006). Market orientation, strategy, and performance in the primary forest industry. Forest Science, 52(3), 209-220. DOI:10.1093/forestscience/52.3.209

[24] He, X., Brouthers, K. D., \& Filatotchev, I. (2018). Market orientation and export performance: The moderation of channel and institutional distance. International Marketing Review, 35(2), 258-279. DOI: 10.1108/IMR-09-2015-0194

[25] Hooley, G., Cox, T., Fahy, J., Shipley, D., Beracs, J., Fonfara, K., \& Snoj, B. (2000). Market Orientation in the Transition Economies of Central Europe: Tests of the Narver and Slater Market Orientation Scales. Journal of Business research, 50(3), 273-285. DOI:10.1016/S0148-2963(99)00105-8

[26] Hu, L. T., \& Bentler, P. M. (1999). Cutoff criteria for fit indexes in covariance structure analysis: Conventional criteria versus new alternatives. Structural equation modeling: a multidisciplinary journal, 6(1), 1-55. DOI:10.1080/10705519909540118

[27] Julian, C. C., Mohamad, O., Ahmed, Z. U., \& Sefnedi, S. (2014). The market orientation-performance relationship: The empirical link in export ventures. Thunderbird International Business Review, 56(1), 97-110. DOI: 10.1002/tie.21598

[28] Kaiser, H. F. (1974). An index of factorial simplicity. Psychometrika, 39(1), 31-36. DOI:10.1007/BF02291575

[29] Kohli, A. K., \& Jaworski, B. J. (1990). Market orientation: the construct, research propositions, and managerial implications. The Journal of Marketing, 54(2), 1-18. DOI: 10.2307/1251866

[30] Kohli, A. K., Jaworski, B. J., \& Kumar, A. (1993). MARKOR: a measure of market orientation. Journal of Marketing research, 30(4), 467-477. DOI: 10.2307/3172691

[31] Matsuno, K., Mentzer, J.T., \& Rentz, J.O. (2005). A conceptual and empirical comparison of three market orientation scales. Journal of business research, 58(1), 1-8. DOI:10.1016/S0148-2963(03)00075-4

[32] Narver, J. C., \& Slater, S. F. (1990). The effect of a market orientation on business profitability. The Journal of Marketing, 54(4), 20-35. DOI: 10.2307/1251757

[33] Navarro, A., Losada, F., Ruzo, E., \& Diez, J. A. (2010). Implications of perceived competitive advantages, adaptation of marketing tactics and export commitment on export performance. Journal of world business, 45(1), 49-58. DOI: 10.1016/j.jwb.2009.04.004 
[34] Njegic,K., \& Djokic, I. (2018). Preduslovi za usvajanje strategije adaptacije cene i njen uticaj na izvozne performanse preduzeca u Srbiji. Skola biznisa, no.1, 1-20. DOI: 10.5937/skolbiz1-19756

[35] Nunnally, J. L. (1978). Psychomeric Theory (2nd ed.). New York: McGraw-Hill.

[36] Olabode, O. E., Adeola, O., \& Assadinia, S. (2018). The effect of export market-oriented culture on export performance: Evidence from a Sub-Saharan African economy. International Marketing Review, 35(4), 637-660. DOI: 10.1108/IMR-08-2016-0167

[37] Racela, O. C., Chaikittisilpa, C., \& Thoumrungroje, A. (2007). Market orientation, international business relationships and perceived export performance. International Marketing Review, 24(2), 144-163. DOI:10.1108/02651330710741794

[38] Radosavljevic, K. (2017). Uticaj marketinški orijentisane strategije na izvozne performance preduzeća/The Imapact of Market-Oriented Strategy on Firms' Export Performance (Doctoral dissertation). Faculty of International Economics, Megatrend University.

[39] Radosavljevic, K., \& Milanovic, V. (2017). Empirical relationship between market orientation and firm's export performance: A comparative review of existing empirical research in the period 1995-2005 with the period 2006-2016. Megatrend revija, 14(3), 165-185. DOI:10.5937/MegRev1703165R

[40] Rojas-Méndez, J. I., \& Rod, M. (2013). Chilean wine producer market orientation: comparing MKTOR versus MARKOR. International Journal of Wine Business Research, 25(1), 27-49. DOI:10.1108/17511061311317291

[41] Ruekert, R. W. (1992). Developing a market orientation: an organizational strategy perspective. International Journal of Research in Marketing, 9(3), 225-245. DOI:10.1016/0167-8116(92)90019-H

[42] Shapiro, P. B. (1988). What the Hell is Market Oriented? Harvard Business Review, 66(6), 119-125.

[43] Shoham, A., Rose, G.M., \& Kropp, F. (2005). Market orientation and performance: a meta-analysis. Marketing Intelligence \& Planning, 23(5), 435-454. DOI:10.1108/02634500510612627

[44] Siguaw, J. A., \& Diamantopoulos, A. (1995). Measuring market orientation: some evidence on Narver and Slater's three-component scale. Journal of Strategic Marketing, 3(2), 77-88. DOI:10.1080/09652549500000005

[45] Sousa, C. M., Lengler, J. F., \& Martínez-López, F. J. (2014). Testing for linear and quadratic effects between price adaptation and export performance: the impact of values and perceptions. Journal of Small Business Management, 52(3), 501-520. DOI: 10.1111/jsbm.12046

[46] Sousa, C. M., Martínez López, F. J., \& Coelho, F. (2008). The determinants of export performance: A review of the research in the literature between 1998 and 2005. International Journal of Management Reviews, 10(4), 343-374. DOI:10.1111/j.1468-2370.2008.00232.x

[47] Takata, H. (2016). Effects of industry forces, market orientation, and marketing capabilities on business performance: An empirical analysis of Japanese manufacturers from 2009 to 2011. Journal of Business Research, 69(12), 5611-5619. DOI: 10.1016/j.jbusres.2016.03.068

[48] Ward, S., Girardi, A., \& Lewandowska, A. (2006). A cross-national validation of the Narver and Slater market orientation scale. Journal of Marketing Theory and Practice, 14(2), 155-167. DOI:10.2753/MTP1069-6679140205

[49] Zehir, C., Köle, M., \& Yýldýz, H. (2015). The mediating role of innovation capability on market orientation and export performance: An implementation on SMEs in Turkey. Procedia-Social and Behavioral Sciences, 207(1), 700-708. DOI: 10.1016/j.sbspro.2015.10.141

Received: 2019-02-15

Revisions requested: 2018-05-05

Revised: 2019-06-24 (2 times)

Accepted: 2019-07-01

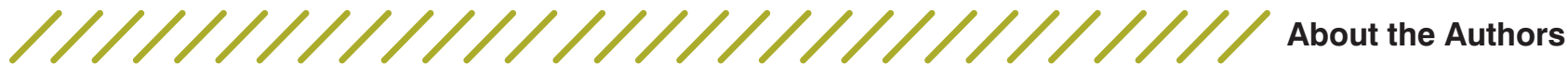

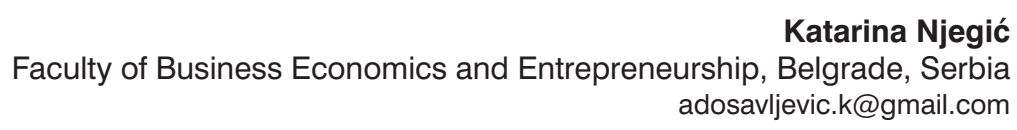

Katarina (Radosavljević) Njegić is an Assistant Professor at the Faculty of Business Economics and Entrepreneurship, at the Department of Economics and Finance, where she has been emplyed since 2010. She received her bachelor's and master's degrees from the Faculty of Organizational Sciences in Belgrade, and her Ph.D. from the Faculty of International Economics (Megatrend University). Her research interests include internatinal business, strategic management, and international marketing, with the focus

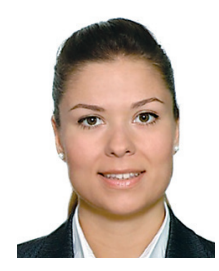
on firm's export performance. 


\author{
Ines Đokić \\ University of Novi Sad, Faculty of Economics in Subotica, Serbia \\ mines@ef.uns.ac.rs
}

Ines Djokic is an Assistant Professor at Faculty of Economics in Subotica, University of Novi Sad. She teaches Marketing communications and Product Design. She is an author and co-author of a number of papers published in journals of international and national importance as well as in proceedings of international scientific conferences. She is also a member of the Serbian Marketing Association (SEMA).

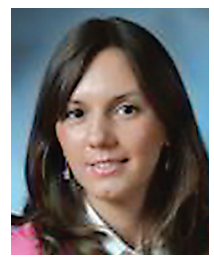

Vesna Milanović

"Union - Nikola Tesla" University, Faculty of Business and Law, Belgrade, Serbia vmilanovic555@gmail.com

Vesna Milanović graduated from the Faculty of Economics at the University of Belgrade in 1989, got her master's degree in 1994 and her PhD degree in 2003. She worked at the Megatrend University from 1999 untill 2017. Since 2017 she has been a Full-time professor (scientific field of economics-marketing) at the Faculty of Business and Law,

"Union - Nikola Tesla" University. Her research areas are marketing, international marketing, management, international business, and nanotechnology. Prof. Milanović is

a researcher (project iii 45003) and she has over 100 published papers. She is a member of the Scientific Society of Economists of Serbia. She is also a member of the Association of Economists and Managers of the Balkans.

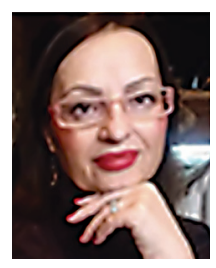

\title{
Appendix
}

Market orientation measurement scale developed by Narver and Slater (1990)

\section{Customer orientation}

*CustOr1: We measure customer satisfaction systematically and frequently

*CustOr2: We constantly monitor our level of commitment and orientation to serving customers' needs

CustOr3: We give close attention to after-sales service

CustOr4: Our business objectives are driven primarily by customer satisfaction

CustOr5: Our strategy for competitive advantage is based on our understanding of customer needs

CustOr6: Our business strategies are driven by our beliefs about how we can create greater value for customers

\section{Competitor orientation}

CompOr1: Top management regularly discusses competitors' strengths and strategies

CompOr2: We rapidly respond to competitive actions that threaten us

*CompOr3: We target customers where we have an opportunity for competitive advantage

CompOr4: Our salespeople regularly share information within our organization concerning competitors' strategies

\section{Interfunctional coordination}

IFC1: All the departments in our company are responsive to each other's needs and requests

IFC2: All of our business functions (e.g., marketing/sales, manufacturing, etc.) are integrated in serving the needs of our target markets

*IFC3: Our top managers from across the company regularly visit our current and prospective customers IFC4: We freely communicate information about our successful and unsuccessful customer experiences across our company

IFC5: Our managers understand how everyone in our business can contribute to creating customer value

\footnotetext{
*items deleted in the refined scale
} 